\title{
DNA bending by negative regulatory proteins: Gal and Lac repressors
}

\author{
Christian Zwieb, Jin Kim, and Sankar Adhya ${ }^{1}$ \\ Laboratory of Molecular Biology, National Cancer Institute, National Institutes of Health, Bethesda, Maryland 20892 USA
}

\begin{abstract}
The ability of two negative regulatory proteins, Gal and Lac repressors, to induce DNA bending was tested by the respective cloning of $\mathrm{gal}$ and lac operator DNA sequences into a sensitive vector, pBend2. pBend2 can generate a large number of DNA fragments in each of which a cloned operator is present in circularly permuted positions along the length of the DNA. Gel electrophoresis of these DNA fragments individually complexed to a repressor shows that the Gal repressor bends both of the gal operators, $O_{\mathrm{E}}$ and $O_{\mathrm{I}}$. Similarly, the Lac repressor induces a bend to a lac operator DNA. In each case, the center of the average bent segment is located at or close to the dyad symmetry axis of the operator sequence. In view of these findings, we discuss how these negative regulatory proteins may function by a more dynamic mechanism than was perceived previously.
\end{abstract}

[Key Words: DNA bending; Gal and Lac repressors; gal and lac operators]

Received January 13, 1989; revised version accepted March 6, 1989.

It is becoming increasingly clear that biological macromolecular reactions involve the formation of specific DNA-multiprotein complexes. For many of these reactions, such as replication or recombination, the complexes assume a higher-order structure (Echols 1986). Implicit in these structures is the winding of specific segments of DNA around one or more of the protein components. To wrap protein with DNA, the latter must either curve or bend (Trifonov and Ulanovsky 1987). DNA curves when the axis of the molecule deviates intrinsically from straightness in a continuous manner, whereas DNA bends when the segment of axis is distorted because of the sequence-specific binding of a protein to that segment. Whether such DNA contortion, demonstrated in replication and recombination complexes (Fuller et al. 1984; Thompson et al. 1984; Leong et al. 1985; Anderson 1986; Dodson et al. 1986; Echols 1986; Koepsel and Kahn 1986; Ryder et al. 1986; Snyder et al. 1986; Hatfull et al. 1987; Robertson and Nash 1988), only helps their stability (Richmond et al. 1984; Travers and Klug 1987), or also has an active role in the processes the complexes carry out, is still open for investigation. In at least one case, a defect in DNA contortion resulted in biochemical inactivity of the system (Newman and Grindley 1984; Hatfull et al. 1987).

DNA contortion also has been implicated in another type of DNA-multiprotein macromolecular reaction, that is, transcription initiation. DNA sequences in or near enhancers or activation sites of transcription initiation are known to curve or show activator-protein-induced bending (Kolb et al. 1983; Bossi and Smith 1984; Wu and Crothers 1984; Kotlarz et al. 1986; Shuey and

\footnotetext{
${ }^{1}$ Corresponding author.
}

Parker 1986; Dripps and Wartell 1987; Mizuno 1987; Plaskon and Wartell 1987). It was suggested by Crothers and Fried (1983) that such contortions may be essential for the formation and activity of the DNA-protein transcription initiation complex. It is very likely that DNA bending facilitates additional protein-protein or protein-DNA contacts that involve the activator protein and RNA polymerase. Contrary to such a direct and active role of an activator protein in controlling transcription initiation positively, the negative regulatory proteins, the repressors, commonly are believed to inhibit transcription initiation by steric hindrance. The binding of a repressor to its binding site, the operator, prevents access of RNA polymerase to the cognate promoter (see Watson et al. 1987). Thus, the role of the repressor is presumed to be passive in gene regulation. Yet, in this paper, we show that at least two repressor proteins, the Gal and Lac repressors, when bound to their specific operators, induce DNA bending. Also, we discuss the potential implication of repressor-induced DNA bending in transcription inhibition.

\section{Results and discussion}

The genetic structure of the control region of the gal operon is shown in Figure 1A. The Gal repressor inhibits transcription by binding to two operators, $O_{\mathrm{E}}$ and $O_{\mathrm{I}}$ (Fritz et al. 1983; Irani et al. 1983; Majumdar and Adhya 1984). $O_{\mathrm{E}}$ and $O_{\mathrm{I}}$ which have similar sequences, are separated from each other and from the promoters. The bendability of the gal operators was monitored by the principle of $\mathrm{Wu}$ and Crothers (1984). Because a bent DNA fragment migrates more slowly in gel electrophoresis compared with a linear fragment of the same size, the degree of electrophoretic mobility retardation of 
A.

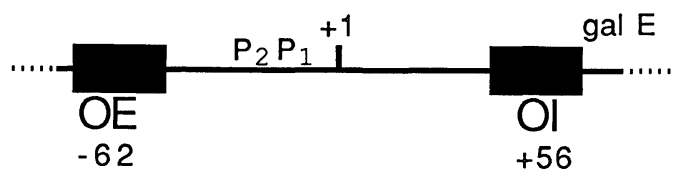

B.

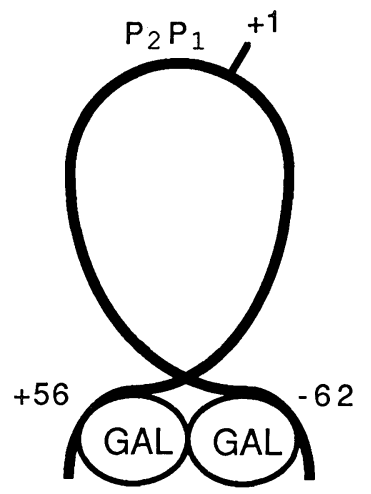

Figure 1. (A) The regulatory region of the gal operon. +1 refers to start site of transcription from the $P 1$ promoter. The location of the two gal operators, $O_{\mathrm{E}}$ and $O_{\mathrm{I}}$ are as shown. Note that $O_{\mathrm{I}}$ is located inside the first structural gene, galE (Irani et al. 1983). $(B) \mathrm{Gal}$ repressors bound to $O_{\mathrm{E}}$ and $O_{\mathrm{I}}$ bend the corresponding DNA segments (this communication) and interact with each other to achieve repression (Majumdar and Adhya 1984; Haber and Adhya 1988). The map is not drawn to scale.

bent DNA that is bound to protein varies with the position of the protein binding site on the DNA.

To generate variations in the position of a gal operator site within a given DNA segment, a sensitive plasmid vector, pBend2, was used (J. Kim, C. Zwieb, C. Wu, and S. Adhya, in prep.). A 236-bp DNA segment that is present between the EcoRI and HindIII restriction sites in the vector contains two restriction sites, SalI and $X b a I$, in the middle for the cloning of a potential bending site. Two sets of 17 restriction sites (denoted by ' $a-q$,' and present in that order, as shown in Fig. 2D/ span the cloning sites. The successive restriction sites are $6 \mathrm{bp}$ apart. Two 30-bp synthetic DNA fragments that contained the $O_{\mathrm{E}}$ and $O_{\mathrm{I}}$ segments (Fig. 2A,B) were cloned into the SalI site to generate the respective clones. The digestion of each of these plasmids with the proper set of restriction enzymes resulted in sets a DNA fragments of identical length in which the $O_{\mathrm{E}}$ or $O_{\mathrm{I}}$ sequence was located in circular permutations with respect to the ends.

After purification, each fragment was labeled at the ends with ${ }^{32} \mathrm{P}$ and labeled DNA extracted by phenol/ chloroform. The Gal repressor-induced DNA bending was monitored for $O_{E}$ and $O_{I}$ sequences by analyzing the differences in the electrophoresis mobilities of these fragments, with and without bound $\mathrm{Gal}$ repressor, in $8 \%$ polyacrylamide gels. The results are shown in Figure 3, $A$ and $B$.

Very few differences in the mobilities of free DNA fragments were noticed, which indicates that these sequences do not generate any intrinsic curving. In contrast, the retarded mobilities of the Gal repressor-bound $O_{E}$ and $O_{I}$ fragments varied considerably. The variations resulted from the positions of the $O_{E}$ and $O_{I}$ sequences in the fragments. In each case, the largest retardation was found when the operator was located near the center of the DNA fragment, whereas the mobilities increased as the operator moved away from the center in either direction. The positioning of the binding site around the central segment of the DNA fragment was less effective in generating mobility differences than the positioning of it around the terminal segments. The quantitative differences in the retardation of the electrophoretic mobilities of the $O_{\mathrm{E}}$ and $O_{\mathrm{I}}$ DNA complexes with the Gal repressor are plotted in Figure 4A. The results show clearly that the binding of the $\mathrm{Gal}$ repressor induces the bending of both $O_{\mathrm{E}}$ and $O_{\mathrm{I}}$. Although the Gal repressor binds to $O_{E}$ and $O_{I}$ with about the same affinity under the conditions of assay (Majumdar and Adhya 1987), it is interesting to note that the binding of the repressor to $O_{I}$ apparently causes a slightly higher degree of bending than does the binding of the repressor to $O_{E}$, as was shown clearly when the two complexes were coelectrophoresed (Fig. 3C). This difference very likely originates from the nonsimilar bases within the 30-bp $O_{\mathrm{E}}$ and $O_{\mathrm{I}}$ fragments that were used in the assay (Fig. 2A,B). Currently, we are investigating operator DNA fragments with altered base pairs to identify bases that may influ-

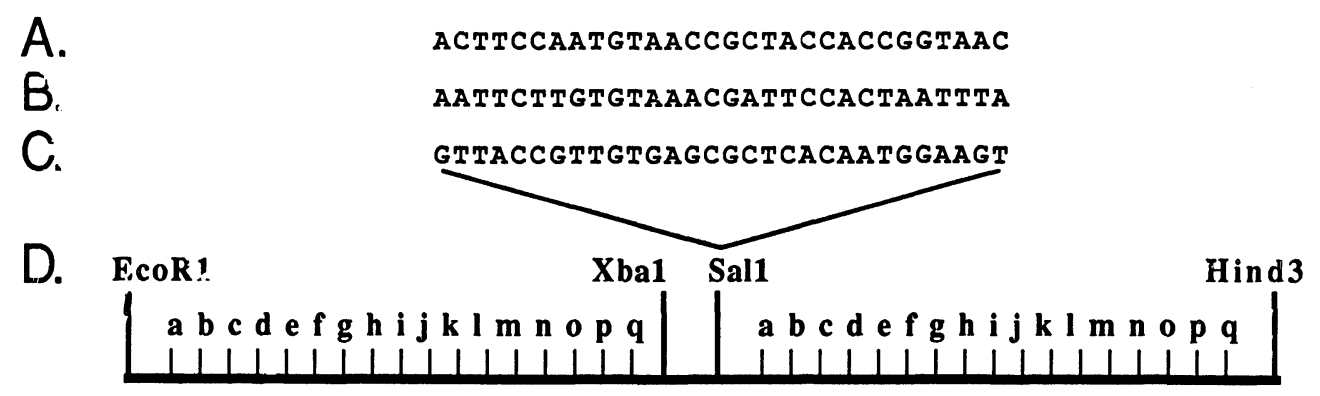

Figure 2. Structure of the relevant portion of pBend2. (Line $A$ ) 30-bp $O_{\mathrm{E}}$ sequence of gal (Irani et al. 1983). (Line $B$ ) 30-bp $O_{\mathrm{I}}$ sequence of $g a l$ (Irani et al. 1983). (Line C) 30-bp sequence of the ideal lac operator sequence in the context of $O_{\mathrm{I}}$ and gal (Simons et al. 1984). (Line $D$ ) The 236-bp DNA segment of the vector located between EcoRI and HindIII sites of pBR322 is shown with 17 duplicated restriction sites a-q: (a) MluI; (b) BglII; (c) NheI; (d) ClaI; (e) StyI; (f) SpeI; (g) XhoI; (h) DraI; (i) EcoRV; (j) PvuII; (k) SmaI; (l) StuI, (m) NruI; $(n)$ SspI; (o) RsaI; $(p)$ NcoI; and $(q)$ BamHI. (The restriction sites are not drawn to scale.) 
Zwieb et al.

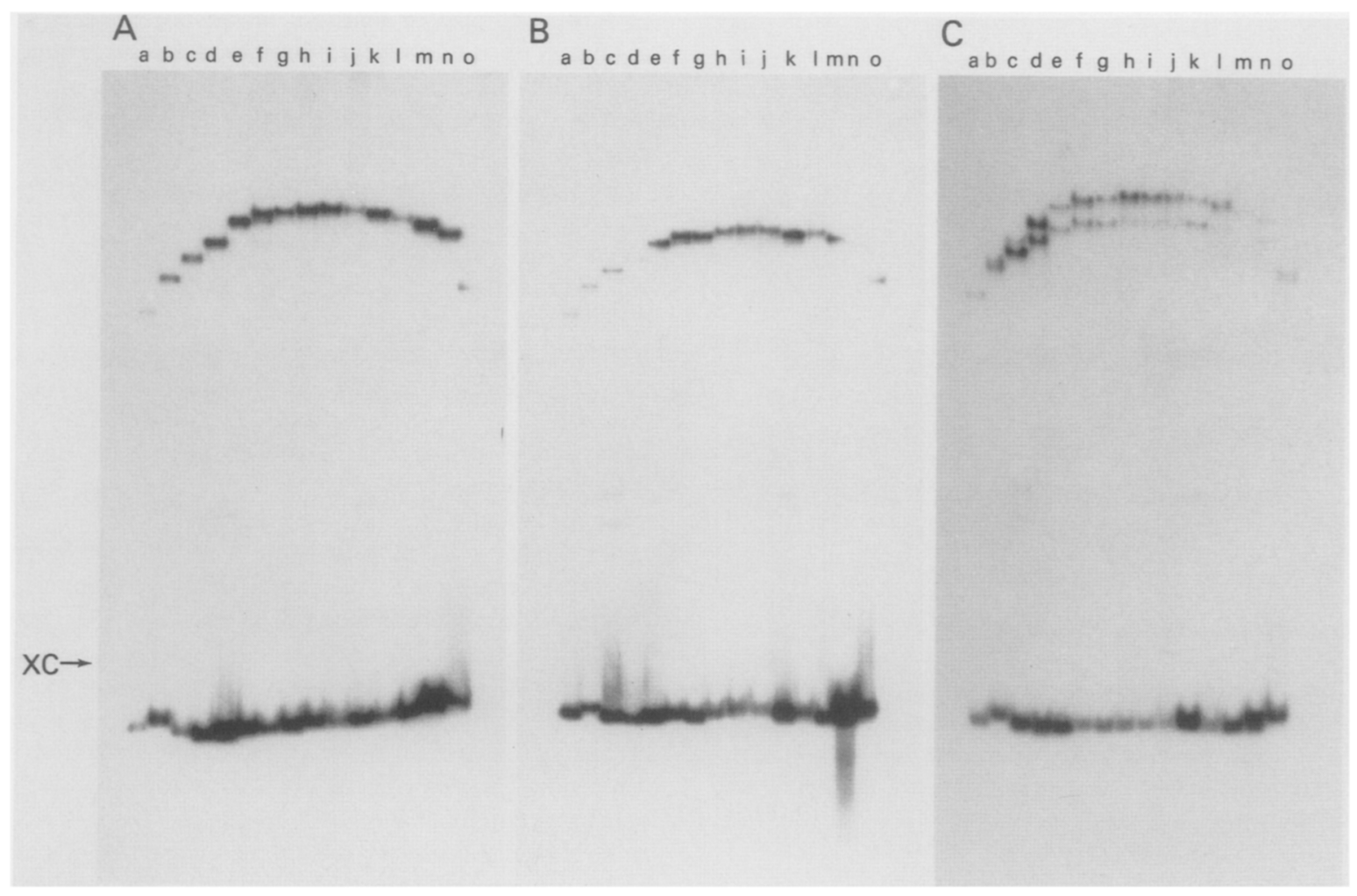

Figure 3. Bending of the two gal operators $\left(O_{\mathrm{I}}, A\right.$; and $\left.O_{\mathrm{E}}, B\right)$ by the binding of the Gal repressor. The Gal repressor was mixed separately with 15 different 5'-end-labeled DNA fragments derived from pBend2. $(C)$ Result of a co-electrophoresis of the $O_{1}$ and the $O_{\mathrm{E}}$ complexes. The 15 restriction sites used were: $(a)$ MluI; $(b)$ BglII; $(c)$ NheI; $(d)$ ClaI; $(e)$ SpeI; $(f)$ XhoI; $(g)$ DraI; $(h)$ EcoRV; $(i)$ PvuII; $(j)$ SmaI; ( $k$ ) StuI; (l) NruI; $(\mathrm{m})$ SspI; $(n)$ RsaI; (o) BamHI. XC denotes the position of xylene cyanol at the end of electrophoresis. In each panel, the slower-moving bands correspond to DNA-protein complexes, whereas the faster-moving bands are free DNA.

A

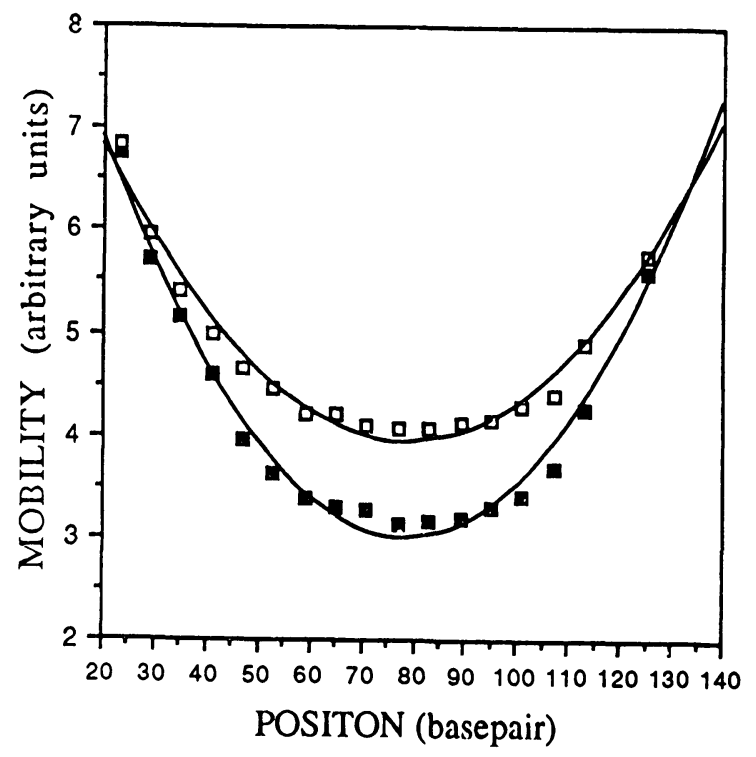

B

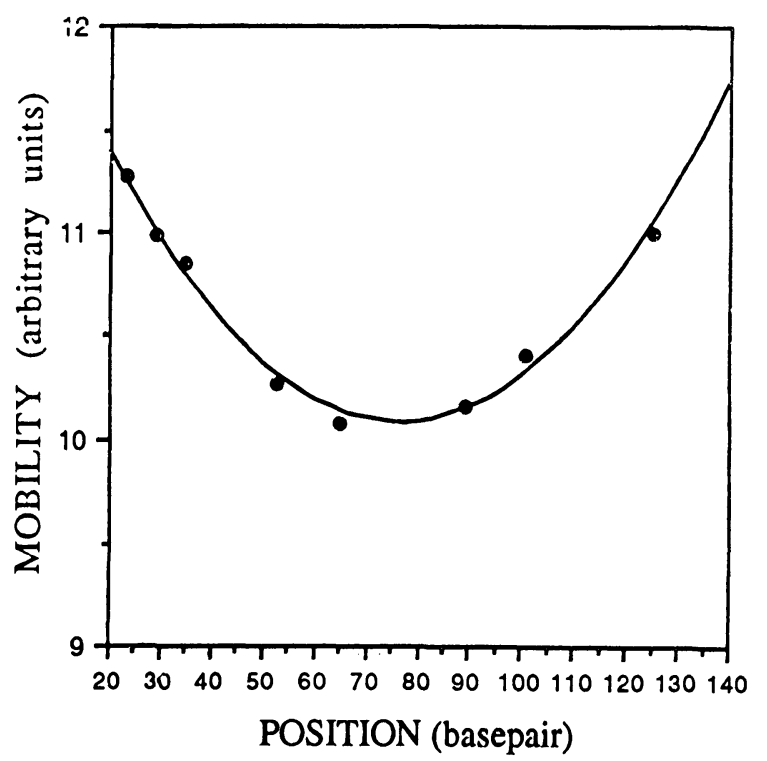

Figure 4. Relative mobility of repressor-operator complexes versus the location of the operator within the 156-bp fragments. $(A)(\square)$ Gal repressor $-O_{\mathrm{E}}$ complex; (-) Gal repressor- $O_{\mathrm{I}}$ complex. $(B)(\bullet)$ Lac repressor-lac operator complex. 
ence the degree of bending. Because the complex with the lowest mobility always occurred with the DNA fragment in which $O_{\mathrm{E}}$ or $O_{\mathrm{I}}$ was located in the middle, it appears that the center of the bent DNA segment, which may have more than one kink, is located at or close to the bases at the dyad symmetry axis of $O_{\mathrm{E}}$ and $O_{\mathrm{I}}$ (Fig. 2A,B).

Because the Lac repressor is a close analog of the Gal repressor both structurally and functionally (von Wilcken-Bergmann and Muller-Hill 1982; Haber and Adhya 1988), we have studied the ability of the Lac repressor to bend the lac-operator DNA sequence. A 30-bp-long synthetic DNA fragment that contained the lac operator sequence was cloned into the Sall site of pBend2, and the electrophoretic mobilities of the DNA fragments generated by restriction digestion were monitored after the binding of the Lac repressor. The 30-bp cloned DNA fragment contained a 16-bp perfect palindromic lac operator sequence, called the ideal lac operator (Simons et al. 1984). The two outer 8-bp sequences are the same as that present in the $O_{\mathrm{I}}$ sequence of $\mathrm{gal}$ (see Fig. 2C). The results of the experiments are shown in Figure 5. It is clear that, although the free DNA fragments do not show any intrinsic curving, the Lac repressor, like the Gal repressor, also induces bending in its cognate operator DNA. The extent of bending is in the same range as bending in the gal operators. As was found with the Gal repressor-operator system, the degree of electrophoretic retardation of the lac operator DNA by the binding of the Lac repressor was highest when the binding site was in the middle and lowest when the binding site was closer to either end of the 150-bp DNA fragment. It is interesting to note that two Lac repressor-operator complexes of slightly different mobilities were observed. The origin of these two complexes presently is being investigated. The relationship between the average mobility of the complexes for each restriction fragment versus the location of the operator in the fragment is shown in Figure 4B.

We have shown previously an interaction between two Gal repressor molecules, bound to $O_{\mathrm{E}}$ and $O_{\mathrm{I}}$, that would result in the formation of a DNA loop (Fig. 1B) (Majumdar and Adhya 1984; Haber and Adhya 1988). The loop, which is expected to be topologically independent of the rest of the DNA, contains the gal promoter region and binds RNA polymerase, as well as cAMP and its receptor protein (CRP) complex even when Gal repressor is occupying $O_{\mathrm{E}}$ and $O_{\mathrm{I}}$ (Adhya and Majumdar 1987; A. Majumdar and S. Adhya, in prep.). We suggest that the Gal repressor does not act by steric hindrance but participates in repression more actively. In this model, the complex made up of DNA, repressor, RNA polymerase, cAMP, and CRP assumes a higher-order structure, which is inactive for transcription initiation (Haber and Adhya 1988). DNA bending induced by the Gal repressor may contribute to the formation of the inactive complex in one or more of the following ways: (1) Bending simply adds to the strength of the repressor-operator contacts (Gartenberg and Crothers 1988). (2) Bending of $O_{\mathrm{E}}$ and $O_{\mathrm{I}}$ is necessary for compaction of the entire DNA-multiprotein complex for facilitating other protein-protein or DNA-protein secondary contacts; without the compaction, these secondary contact points, which are essential for repression, may be spaced apart. (3) CRP also induces bending in DNA /Gartenberg and Crothers 1988; Heumann et al. 1986); CRP-induced bending results in close DNA-protein contacts and also may have long-range effects on DNA regions beyond their immediate contact sites (Gartenberg and Crothers 1988; Crothers and Fried 1983). Likewise, DNA bending at $O_{\mathrm{E}}$ and $O_{\mathrm{I}}$ bound to the Gal repressor may exert an effect on the neighboring promoter DNA domain (loop) in such a way that bound RNA polymerase fails to initiate from it. (4) If bending that is induced by CRP (Crothers and Fried 1983) or RNA polymerase (Kunke et al. 1987) is necessary for transcription, the Gal repressor

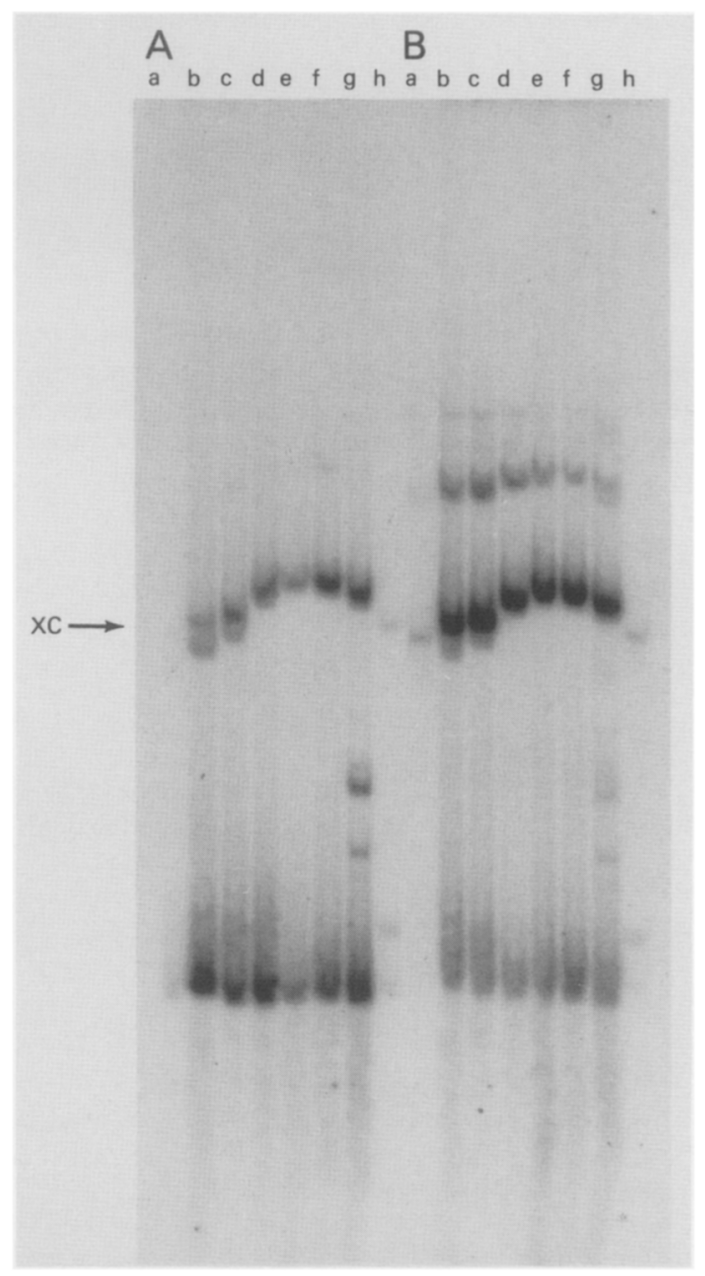

Figure 5. Bending of the lac operator DNA by the Lac repressor. The Lac repressor was bound to eight different lac operator DNA fragments. The eight restriction sites used for this experiment were: (a) MluI; (b) BglII; (c) NheI; (d) SpeI; (e) DraI; (f) StuI; $(g)$ SspI; (h) BamHI. (A) $2.4 \mathrm{ng}$ of the Lac repressor was used in each reaction. $(B) 7.2 \mathrm{ng}$ of the Lac repressor was used in each reaction. At this higher concentration of repressor, other bands of Lac repressor-operator complexes were observed as has been reported before (Fried and Crothers 1983). 
acts to straighten out the DNA by bending it in the direction opposite to that required for transcription.

It has been noted previously that the binding of the Lac repressor to a DNA fragment that contains a natural lac operator does not induce bending ( Wu and Crothers 1984), although it was pointed out subsequently that a difference in the mobility of two repressor-operator complexes results from a difference in location of the operator in the DNA fragment (Kramer et al. 1987). By use of the pBend2 system, we observed Lac-repressor-induced bending even under conditions used by the previous authors. The observation of Lac-repressor-induced DNA bending in our system is not a result of an aberrant position-related movement of the complex under electrophoretic force through the gel pores. Unlike the Gal and Lac repressors, the mobilities of another DNA binding protein $\mathrm{Cro}^{\lambda}$ when complexed to its operator permutations do not show significant difference when analyzed in the pBend2 system (C. Zwieb, in prep.). However, if DNA bending that is induced by Gal repressor activity contributes to repression of the gal operon, as discussed above, then our results are consistent with the previous observations that the Lac repressor can also repress the gal operon from nonoverlapping distal sites when the two gal operators, $O_{E}$ and $O_{\mathbf{L}}$ are converted into two lac operator DNA sequences (Haber and Adhya 1988). From these results, we propose that, for both gal and lac systems, formation of a higherorder complex, in which the DNA is contorted by the corresponding repressor in a similar fashion, is crucial for gene repression.

\section{Materials and methods}

Strain, plasmid, and reagents

The Escherichia coli strain used for plasmid growth and construction was RR1 (F, hsdS20, proA2, lacY1, galK2, rpsSL20, xy15, mt11, supE44). The restriction endonucleases, the $\mathrm{T} 4$ polynucleotide kinase, and the DNA sequencing kit were obtained from BRL. The plasmid $p B e n d 2$ is a derivative of $\mathrm{pBR} 322$ and contains a 236-bp EcoRI-HindIII DNA fragment with two sets of 17 restriction sites in direct repeat as well as unique $\mathrm{XbaI}$ and SalI sites between the two repeats (J. Kim, C. Zwieb, C. Wu, and S. Adhya, in prep.; see Fig. 2D).

\section{DNA cloning}

Oligonucleotides that contained various operator sequences were prepared in an Applied Biosystems DNA synthesizer. Equal amounts of two complementary oligonucleotides were annealed (without further purification) in $10 \mathrm{~mm}$ Tris- $\mathrm{HCl}, 1$ mM EDTA, $100 \mathrm{~mm} \mathrm{NaCl}$ by heating at $95^{\circ} \mathrm{C}$ for $5 \mathrm{~min}$ in a small water bath and slow-cooling to room temperature for 4 hr. Annealed oligonucleotides were extracted once with phenol/chloroform and precipitated with three volumes of ethanol with the addition of $5 \mathrm{M} \mathrm{NaCl}$ to $300 \mathrm{~mm}$ final concentration. The material was washed, dried, and dissolved in a small volume of water and stored at $-20^{\circ} \mathrm{C}$.

Annealed oligonucleotides were treated in a $25-\mu l$ reaction volume with T4 polynucleotide kinase in kinase buffer and ATP for $15 \mathrm{~min}$ at $37^{\circ} \mathrm{C}$ as recommended by BRL. The annealed oligonucleotides were cloned into the SalI site of pBend2 after the SalI site was filled in with Klenow enzyme and then ligated in the presence of T4 DNA ligase and ATP in ligase buffer (as recommend by BRL) under conditions of 50 -fold molar excess of oligonucleotides over pBend2 DNA in a reaction volume of 35 $\mu l$. The ligation was first carried out at room temperature for 3 $\mathrm{hr}$ and then continued at $4^{\circ} \mathrm{C}$ overnight. Ten microliters of the ligation mixture were used for transformation of competent RR1 cells. Transformants were selected on LB-Ampicillin plates and screened for the presence of the operator sequence by appropriate restriction enzyme analysis. The correct clones were confirmed by DNA sequencing (Sanger 1977).

\section{Isolation and labeling of DNA fragments}

The restriction enzymes indicated in the legends of Figures 3 and 5 were used to generate fragments of 155 -bp lengths. The fragments were separated by electrophoresis on $2 \%$ agarose gels and visualized by ethidium bromide staining. DNA fragments were extracted from the cut gels by the addition of phenol, by freezing, and by centrifugation for $10 \mathrm{~min}$. DNA fragments were recovered after two additional phenol/chloroform and one chloroform extraction and precipitation with 3 volumes of ethanol in the presence of $300 \mathrm{~mm}$ sodium acetate (pH 6.0). DNA fragments were stored in water at $-70^{\circ} \mathrm{C}$. An aliquot of DNA was used for labeling with T4 polynucleotide kinase and [ $\boldsymbol{\gamma}^{-32}$ P]ATP (Amersham) as recommended by BRL. The labeled DNA was extracted with phenol/chloroform as described above and stored at $-70^{\circ} \mathrm{C}$.

\section{DNA-repressor complex formation and gel electrophoresis}

Gal repressor purification has been described previously (Majumdar et al. 1987). Purified Lac repressor was a gift of Joan Betz of the University of Colorado. Gal repressor-DNA complexes were formed and electrophoresed as established before (Majumdar and Adhya 1984). An assay mixture of $20 \mu \mathrm{l}$ that contained $20 \mathrm{~mm}$ Tris- $\mathrm{HCl}(\mathrm{pH} 8.0), 40 \mathrm{mM} \mathrm{KCl}, 10 \mathrm{mM} \mathrm{MgCl}_{2}$, $1 \mathrm{mM}$ dithiothreitol, $1 \mathrm{mM}$ EDTA, $50 \mu \mathrm{g} / \mathrm{ml}$ of bovine serum albumin, 1-10 ng of 5'-end-labeled ${ }^{32} \mathrm{P}-\mathrm{DNA}$ and 2-20 nM repressor to result in approximately equal molar amount of free DNA and DNA-protein complex after electrophoretic separation in $8 \%$ polyacrylamide gels that contained $0.125 \%$ bisacrylamide in $0.089 \mathrm{M}$ Tris-borate $(\mathrm{pH} 8.3)$ and $0.002 \mathrm{M}$ EDTA. The binding of the Lac repressor to ${ }^{32} \mathrm{P}$-labeled DNA and the electrophoretic separation of the complex from free DNA on $4 \%$ gels was done as described by Fried and Crothers (1983). Gels were dried on Whatman 3MM paper for autoradiography.

\section{Acknowledgments}

We thank Alokes Majumdar and Carl Wu for valuable discussions and assistance, Joan Betz for a gift of Lac repressor, and Althea Gaddis for typing the manuscript.

\section{References}

Adhya, S. and A. Majumdar. 1987. Negative control of the gal operon. In RNA polymerase and regulation of transcription (ed. W.S. Reznikoff, R.R. Burgess, J.E. Dahlberg, C.A. Gross, M.T. Record, and M.P. Wickens), pp. 129-135. Elsevier Science Publishers, New York.

Anderson, J.N. 1986. Detection, sequence patterns, and function of unusual DNA structures. Nucleic Acids Res. 14: 8513-8533.

Bossi, L. and D.M. Simth. 1984. Conformational change in the 
DNA associated with an unusual promoter mutation in a tRNA operon of Salmonella. Cell 39: 643-652.

Crothers, D.M. and M.G. Fried. 1983. Transmission of longrange effects in DNA. Cold Spring Harbor Symp. Quant. Biol. 47: 263-269.

Dodson, M., H. Echols, S. Wickner, C. Alfano. K. MensaWilmot, B. Gomes, J. Lebowitz, J.D. Roberts, and R. McMacken. 1986. Specialized nucleoprotein structures at the origin of replication of bacteriophage $\lambda$ : Localized unwinding of duplex DNA by a six-protein reaction. Proc. Natl. Acad. Sci. 83: 7638-7642.

Dripps, D. and R.M. Wartell. 1987. DNA bending induced by the catabolite activator protein allows ring formation of a 144-bp DNA. J. Biomolec. Struct. Dyn. 5: 1-13.

Echols, H. 1986. Multiple DNA-protein interactions governing high-precision DNA transactions. Science 233: 1050-1056.

Fried, M.G. and D.M. Crothers. 1983. CAP and RNA polymerase interactions with the lac promoter: Binding stoichiometry and long-range effects. Nucleic Acids Res. 11: 141158.

Fritz, H.-J., H. Bicknase, B. Gleumes, C. Heibach, S. Rosahl, and R. Ehring. 1983. Characterization of two mutations in the Escherichia coli galE gene inactivating the second galactose operator and comparative studies of repressor binding. $E M B O$ J. 2: 2129-2135.

Fuller, R.S., B.E. Funnell, and A. Kornberg. 1984. The dnaA protein complex with the $E$. coli chromosomal replication origin (oriC) and other DNA sites. Cell 38: 889-900.

Gartenberg, M.R. and D.M. Crothers. 1988. DNA sequence determinants of CAP-induced bending and protein binding affinity. Nature 333: 824-829.

Haber, R. and S. Adhya. 1988. Interaction of spatially separated protein-DNA complexes for control of gene expression: Operator conversions. Proc. Natl. Acad. Sci. 85: 9683-9687.

Hatfull, G.F., S.M. Noble, and N.D.F. Grindley. 1987. The $\gamma \delta$ resolvase induces an unusual DNA structure at the recombinational crossover point. Cell 49: 103-110.

Heumann, H., W. Metzger, and M. Niehorster. 1986. Visualization of intermediary transcription rates in the complex between Escherichia coli DNA-dependent RNA polymerase and a promoter-carrying DNA fragment using the gel retardation method. Eur. J. Biochem. 158: 575-579.

Irani, M., L. Orosz, and S. Adhya. 1983. A control element within a structural gene: The gal operon of Esherichia coli. Cell 32: 783-788.

Koepsel, R.R. and S.A. Kahn. 1986. Static and initiator proteinenhanced bending of DNA at a replication origin. Science 233: $1316-1318$

Kolb, A., A. Spassky, C. Chapon, B. Blazy, and H. Buc. 1983. On the different binding affinities of CRP and at the lac, gal and malT promoter regions. Nucleic Acids Res. 11: 7833-7852.

Kotlarz, D., A. Fritsch, and H. Buc. 1986. Variations of intramolecular ligation rates allow the detection of protein-induced bends in DNA. EMBO I. 5: 799-803.

Kramer, H., M. Niemoller, M. Amouyal, B. Revet, B. von Wilcken-Bergmann, and B. Muller-Hill. 1987. lac repressor forms loops with linear DNA carrying two suitably placed operators. EMBO J. 6: 1481-1491.

Kunke, G., H.-J. Fritz, and R. Ehring. 1987. Unusual properties of promoter-up mutations in the Escherichia coli galactose operon and evidence suggesting RNA polymerase-induced DNA bending. EMBO I. 6: 507-513.

Leong, J.M., S. Nunes-Duby, C.F. Lesser, P. Youderian, M.M. Susskind, and A. Landy. 1985. The $\pi 80$ and P22 attachment sites. Primary structure and interaction with Escherichia coli integration host factor. J. Biol. Chem. 260: 4468-4477.
Majumdar, A. and S. Adhya. 1984. Demonstration of two operator elements in gal: In vitro repressor binding studies. Proc. Natl. Acad. Sci. 81: 6100-6104.

1987. Probing the structure of the Gal operator-repressor complexes: Conformation change in DNA. J. Biol. Chem. 262: 13258-13262.

Majumdar, A., S. Rudikoff, and S. Adhya. 1987. Purification and properties of gal repressor: $p L-g a l R$ fusion in $\mathrm{pKC} 31$ plasmid vectors. J. Biol. Chem. 262: 2326-2331.

Mizuno, T. 1987. Static bend of DNA helix at the activator recognition site of the omp F promoter in Escherichia coli. Gene 54: 57-64.

Newman, B.J. and N.D.F. Grindley. 1984. Mutants of the $\gamma \delta$ resolvase: A genetic analysis of the recombination function. Cell 38: 463-469.

Plaskon, R.R. and R.W. Wartell. 1987. Sequence distributions associated with DNA curvature are found upstream of strong E. coli promoters. Nucleic Acids Res. 15: 785-796.

Richmond, T.J., J.T. Finch, B. Rushton, D. Rhodes, and A. Klug. 1984. Structure of the nucleosome core particle at $7 \AA$ resolution. Nature 311: 532-537.

Robertson, C.A. and H.A. Nash. 1988. Bending of the bacteriophage $\lambda$ attachment site by Escherichia coli integration host factor. J. Biol. Chem. 263: 3554-3557.

Ryder, K., S. Silver, A.L. DeLucia, E. Fanning, and P. Tegtmeyer. 1986. An altered DNA conformation in origin region $\mathrm{I}$ is a determinant for the binding of SV40 large T antigen. Cell 44: 719-725.

Sanger, F., S. Nicklen, and A.R. Coulson. 1977. DNA sequencing with chain terminating inhibitors. Proc. Natl. Acad. Sci. 74: 5463-5467.

Shuey, D.J. and C.S. Parker. 1986. Bending of promoter DNA on binding of heat shock transcription factor. Nature 323: 459-461.

Simons, A., D. Tils, B. von Wilcken-Bergmann, and B. MullerHill. 1984. Possible ideal lac operator: Escherichia coli lac operator-like sequences from eukaryotic genomes lack the central G.C. pair. Proc. Natl. Acad. Sci. 81: 1624-1628.

Snyder, M., A.R. Buchman, and R.W. Davis. 1986. Bent DNA at a yeast autonomously replicating sequence. Nature 324: 87-89.

Thompson, R., L. Taylor, K. Kelley, R. Everett, and N. Willets. 1984. The F plasmid origin of transfer: DNA sequence of wild-type and mutant origins and location of origin specific nicks. $E M B O J$. 3: 175-1180.

Travers, A. and A. Klug. 1987. DNA wrapping and writhing. Nature 327: 280-281.

Trifonov, E.N. and L.E. Ulanovsky. 1987. Inherently curved DNA and its structural elements. In Unusual DNA structures. (ed. R.D. Wells and S.C. Harvey), pp. 173-187. Springer-Verlag, Berlin.

von Wilcken-Bergmann, B. and B. Muller-Hill. 1982. Sequence of galR gene indicates a common evolutionary origin of lac and gal repressor in Escherichia coli. Proc. Natl. Acad. Sci. 79: 2427-2431.

Watson, J.D., N.H. Hopkins, J.W. Roberts, J.A. Steitz, and A.M. Weiner. 1987. Molecular biology of the gene. pp. 465-502. The Benjamin-Cummings Publishing Co.

Wu, H.-M. and D.M. Crothers. 1984. The locus of sequence-directed and protein-induced DNA bending. Nature 308: 509513.

Zahn, K. and F. Blattner. 1987. Direct evidence for DNA bending at the Lambda replication origin. Science 236: 416422. 


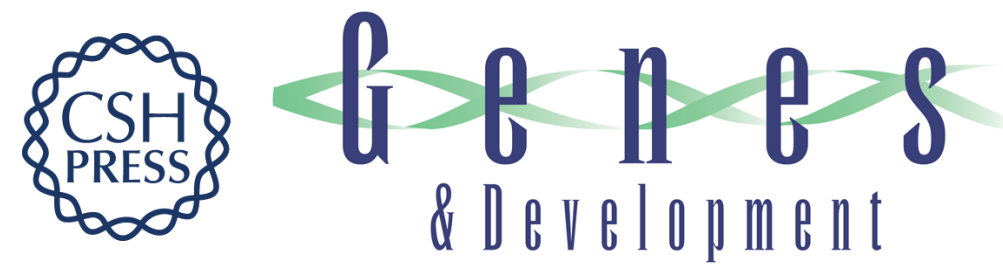

\section{DNA bending by negative regulatory proteins: Gal and Lac repressors.}

C Zwieb, J Kim and S Adhya

Genes Dev. 1989, 3:

Access the most recent version at doi:10.1101/gad.3.5.606

References This article cites 38 articles, 14 of which can be accessed free at:

http://genesdev.cshlp.org/content/3/5/606.full.html\#ref-list-1

License

Email Alerting Receive free email alerts when new articles cite this article - sign up in the box at the top Service right corner of the article or click here.

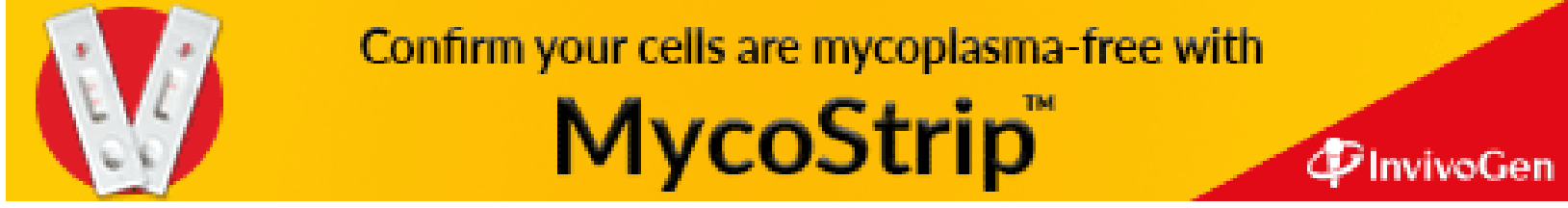

